\title{
Study of Unconventional Alternatives to Vertical Breakwater
}

\author{
Karim Badr Hussein and Mohamed Ibrahim \\ Lecturer of Irrigation and Hydraulics, Faculty of Engineering, Al-Azhar University \\ Corresponding author E-mail: badrkarim713@yahoo.com
}

\begin{abstract}
The main objective of the breakwaters is to protect the port, the beach or the beach facilities from strong waves and storms, as they help to establish calm inside the port and thus achieve safety for ships, and ease of operation. This research aims to present study unconventional alternatives to vertical breakwater. In this study, two different models of vertical wave barriers implemented were chosen for their study and evaluation of the hydrodynamic performance. The first model is a vertical wall with circular slots and the second model is a vertical wall with square slots. A comparison was made between the two models it was found that the square slots reduce the transmission of waves more than circular slots by 5 to $20 \%$. The use of two circular slotted walls decreases wave transmission by up to $30 \%$ and increases wave energy dissipation by up to $40 \%$ as compared to a single wall. With increasing relative length $(h / L)$, the horizontal wave force rises. The relative wave forces $(\mathrm{F} / \mathrm{Fo})$, at porosity $(\varepsilon)=0.25$, was greater than at porosity $(\varepsilon)=0.50$ by 10 to $30 \%$. At the openings, the wave velocity is high, and the wave energy dissipation factor was also high; the higher the wave amplitude, the greater the wave energy dissipation factor.
\end{abstract}

Key words: Coastal, Breakwater, FLOW-3D, Numerical Models, Energy Dissipation, Vertical Wall.

\section{INTRODUCTION}

In every country, the coastal zone is one of the most significant and crucial. The coastal area and ports have very large economic impacts as they contribute to many different fields such as: promoting foreign trade, developing and reviving tourism on the coasts, It also contributes to the establishment of urban neighborhoods and stability, in addition to giving new job possibilities with strong returns for young people and constructing fishing ports that boost fish riches. [1]. However, natural phenomena like as waves, winds, tides, and currents near to the coastline have an impact on the beaches and the coastal region's stability. Therefore, coastal conservation services play an important role in maintaining and preserving the coastal environment's equilibrium. A break water wall that protects the harbor, and beach facilities from strong waves.

The breakwater provides a quiet area, where ships can dock safely and provides temporary protection during construction and discovery of oil and minerals. The waves lose a lot of their energy when hitting the breakwater. Breakwaters may be visible, floating, or underwater and come in a range of sizes, materials, and output standards [11]. Traditional barriers, or visible bulkheads, have extremely efficient, but they obscure the aesthetic vision of the beach. They necessitate a large number of building materials, as well as a rising construction expense [9]. Floating barriers, on the other hand, needless materials and have a lower construction cost, but their effectiveness is limited. As a result, submerged partitions are regarded as one of the better options because they prevent the disadvantages of these varieties. Submerged barriers are one of the most significant beach defense facilities, and one of the benefits of submerged barriers is that they are comparatively inexpensive to construct compared to transparent barriers, and they enable water to flow from front to back [3].

Under the membrane, water regenerates. It also has a minimal effect on neighboring beaches, as it does not distort the aesthetic image of the ocean, and does not obstruct the view [18]. Submerged breakwaters, on the other hand, lose their effectiveness in dispersing wave energy and defending shorelines as they subside after building. The barrier's quality is also affected by the high water level. As a result, one of the most critical aspects of coastal protection is improving the effectiveness of underwater breakwaters. Vertical breakwaters this type of barriers is installations that have vertical faces towards the sea [10]. These barriers work to prevent part of the wave energy from reaching the shore or the water area to be protected and thus the waves calm down [16].

Vertical breakwaters may consist of blocks, caissons, sheet piles, or cellular. This study aims to present a study of the hydrodynamic performance of a perforated vertical breakwater with square and circular holes. This paper has also been compared to similar studies in this field, as well as the hydrodynamic efficiency of the proposed models. This is presented in this paper under the following headlines:

- Materials and methods.

- Results and discussion.

- Conclusions and recommendations.

\section{MATERIALS AND METHODS}

\section{A. The Open Channel}

Several experiments were performed in the hydraulics laboratory at Zagazig University's Faculty of Engineering. An open channel was used for the experimental investigation. The flume dimensions were $12 \mathrm{~m}, 2.00 \mathrm{~m}$ and $1.20 \mathrm{~m}$ (length, width and height) respectively and depth of water (h) was = $0.40 \mathrm{~m}$. The gravel wave absorber, which has a 3:1 slope, was installed in the exit zone to absorb the waves which have been transmitted. The walls of the open channel were made of reinforced concrete, Fig. 1. The waves were developed using linear wave theory, and the wave length can be calculated using the equation below $[2,17]$ :

$$
L=\frac{g T^{2}}{2 \pi} \tanh (k h)
$$




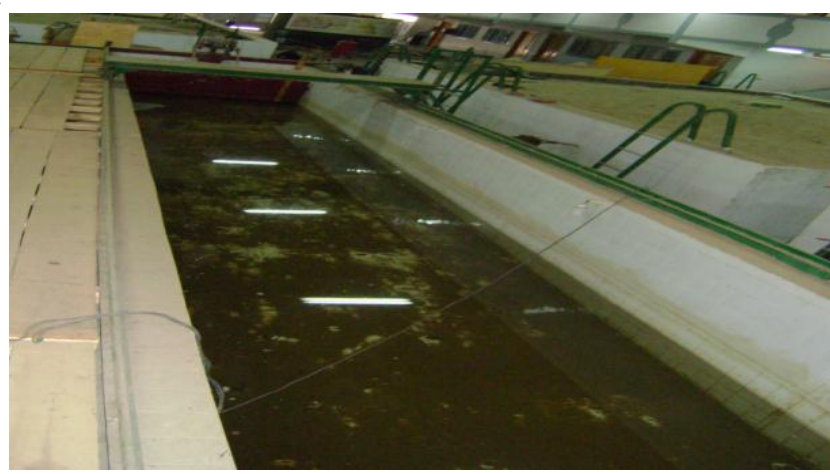

Fig. 1. The open channel

Experimental wave properties, wave incident (Hi), and wave period (T) were used in the numerical model to test proposed breakwater and study its hydrodynamic efficiency.

\section{B. FLOW 3D Model}

This paper used FLOW 3D to numerically model the proposed breakwater. FLOW 3D is a popular computational fluid dynamics (CFD) software that can help to understand a variety of physical flow processes. It solves the threedimensional Navier-Stokes and continuity equations using an ordered, rectangular grid [13]. The Equations below summarize the general mass continuity equations used by FLOW 3D for three dimensional incompressible flows. It's worth noting that (CFD) software is widely used in all engineering disciplines, especially in marine and coastal engineering. The FLOW 3D numerical model has the benefit of satisfying engineering and hydraulic boundary conditions.

\section{Numerical Molding}

To apply the model and generate several scenarios for numerical simulation of the proposed breakwater, numerical molding FLOW 3D was used. In this model, two separate grids of different cell sizes were used to achieve a convenient balance between precision/accuracy and time measurement [4]. Low frequency waves have mesh cells that are $1 \mathrm{~cm}$ in diameter in each direction, and high frequency waves have mesh cells that are $0.5 \mathrm{~cm}$ in diameter for each direction [15]. To avoid any recoveries, whether from the open channel's end or the wave paddle, it's critical to analyze the time frame for measuring the wave height according to the wavelength. It's crucial to calculate the height of the event spectrum's reflected and emitted waves. As a result, using the wave profiles derived from, the reflection factor "kr" is estimated [14]:

$$
k r=\frac{H r}{H i}
$$

Where: Hr is stand for the height of the reflected wave and $\mathrm{Hi}$ is height of the incident wave.

Using the following equation, the transmission factor" kt" was calculated from the wave transmission profile:

$$
k t=\frac{H t}{H i}
$$

Using the above equations and the following relationship, the energy dissipation factor "kd" can be determined $[5,6]$ :

$$
k d=1-k r^{2}-k t^{2}
$$

Figure 2 shows models of breakwaters: a) perforated wall with circular slots, and b) perforated wall with square slots. Numerical modeling of the breakwater models was done in various forms, as shown in figure 2, and the characteristics are as follows: $h$ was the constant water depth in still water; open channel had a rectangular cross section $(0.3 \times 0.6 \times 13$ $\mathrm{m})$; B was the distance between the centerlines of the two walls; $b$ was the thickness of the first and the second walls. Breakwater simulations were put to the test in $0.4 \mathrm{~m}$ of water with varying wave heights. Table 1 shows the domains of the investigated variables. In addition, this breakwater was modeled numerically in Flow 3D as presented figure 3. Three treads were discovered using a numerical model (Flow 3D). The first was the dimension of the open channel, as well as the mesh and breakwater elements. The algorithm solves the second tread in this tread, and the last tread outputs data processing results.

Table 1- Domains of variables.

\begin{tabular}{|l|c|}
\hline Different factors & Domain \\
\hline Water depth $(\mathrm{m})$ & 0.40 \\
\hline Wave periods $(\mathrm{s})$ & $0.90,1.1,1.2,1.3,1.4,1.6,1.8$, \\
\hline Length of wave $(\mathrm{m})$ & 1.20 to 3.75 \\
\hline Incident wave height $(\mathrm{m})$ & 0.042 to 0.13 \\
\hline Breakwater thickness $(\mathrm{cm})$ & 2.50 \\
\hline porosity $(\varepsilon)$ & 0.50 \\
\hline Distance between walls $(\mathrm{m})$ & 0.40 \\
\hline
\end{tabular}

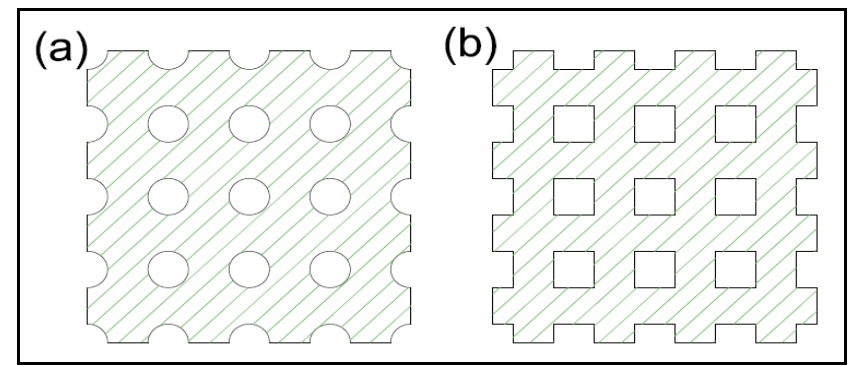

Fig. 2. Breakwaters model (a) perforated wall with circular slots and (b) perforated wall with square slots.

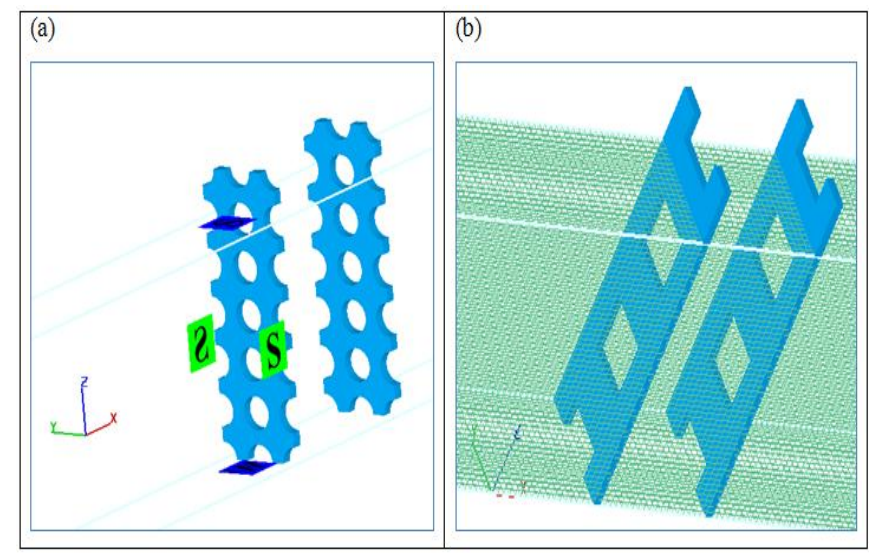

Fig. 3. Breakwaters model in Flow-3D with meshing geometry and boundary (a) circular slots (b) square slots. 


\section{Hydrodynamic Force}

One of the most important parameters in this study is the hydrodynamic force. As seen in figure 4, the hydrodynamic forces were calculated by averaging the pressure across the wetted surface of the body. Bernoulli's modified linear can be used to express the hydrodynamic pressure (p) as seen following:

$$
\begin{aligned}
& p=-\rho\left(\frac{\partial \phi}{\partial}\right)_{x=-a}=i \omega \rho\left(\phi_{1}-\phi_{2}\right)_{x=-a} \\
& p=-\rho\left(\frac{\partial \phi}{\partial}\right)_{x=a}=i \omega \rho\left(\phi_{2}-\phi_{3}\right)_{x=a} \\
& p=\frac{-\rho g H_{i}}{2} \frac{\cosh k(z+h)}{\cosh k h}\left(1+k_{r}-k_{t}\right)
\end{aligned}
$$

Following the determination of the hydrodynamic pressure (p), the hydrodynamic forces $\left(\mathrm{F}^{*}\right)$ occurring on the breakwater can be calculated using the formulas below [7, 13]:

$$
\begin{aligned}
& F^{*}=\int_{-d}^{0} p(0, z) d z \\
& F^{*}=-\frac{\rho g H_{i}}{2 k}\left(1+k_{r}-k_{t}\right) \tanh k h \\
& F=\operatorname{Re}\left[F^{*} e^{-i \omega t}\right]
\end{aligned}
$$

$\mathrm{F}_{0}$ are due to fully standing waves,

$$
\left.\mathrm{F}_{0}=\rho g H i \tanh (\mathrm{kh}) / \mathrm{k}\right)
$$

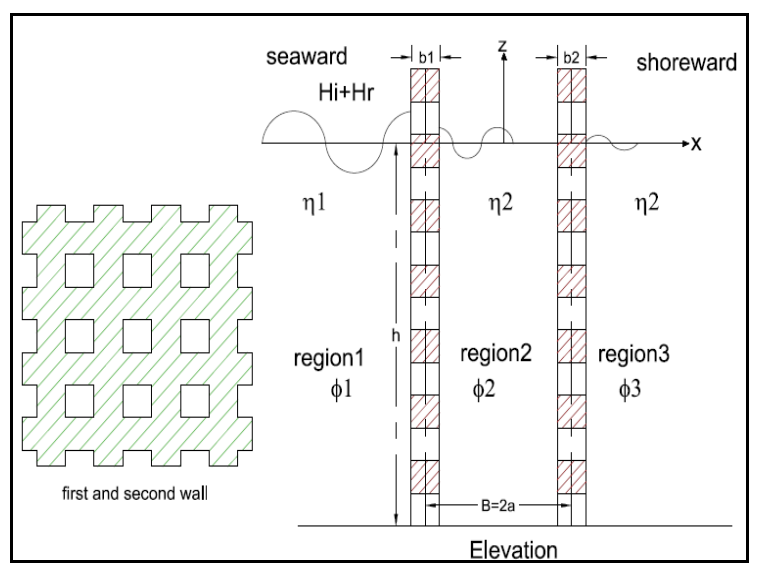

Fig. 4. Details and dimensions of proposed breakwater

\section{RESULTS AND DISCUSSION}

After audition proposed models numerically by flow-3d obtain on many of results. Figures 5 and 6 show wave profiles using (Flow-3D) at wave period $(\mathrm{T})=1.2 \mathrm{sec}$ for perforated walls with circular and square slots at behind model. Wave profile consists under wave period $(\mathrm{T})=1.2$ sec and wave elevation showed after passes three seconds. Notice that the difference between two proposed breakwaters about $10 \%$.

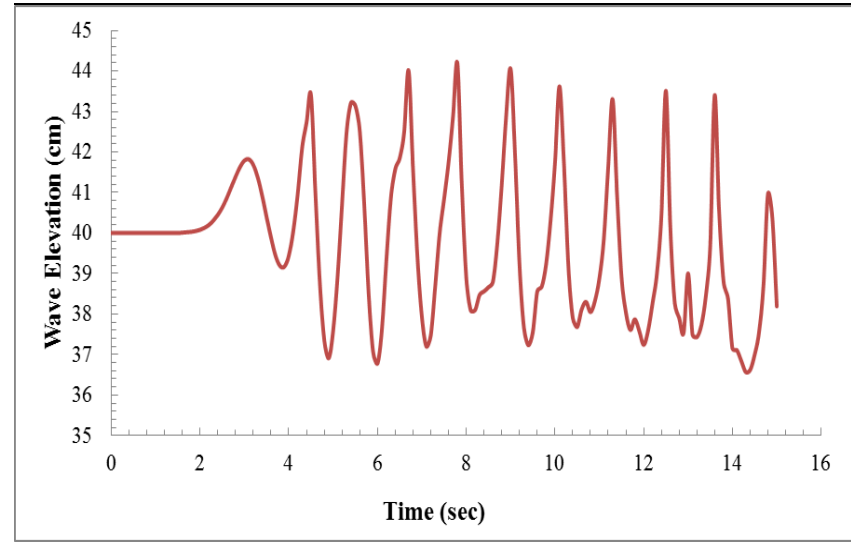

Fig 5.Wave profiles using (Flow-3D) at wave period $(\mathrm{T})=1.2 \mathrm{sec}$ for perforated walls with circular slots at behind model (Ht).

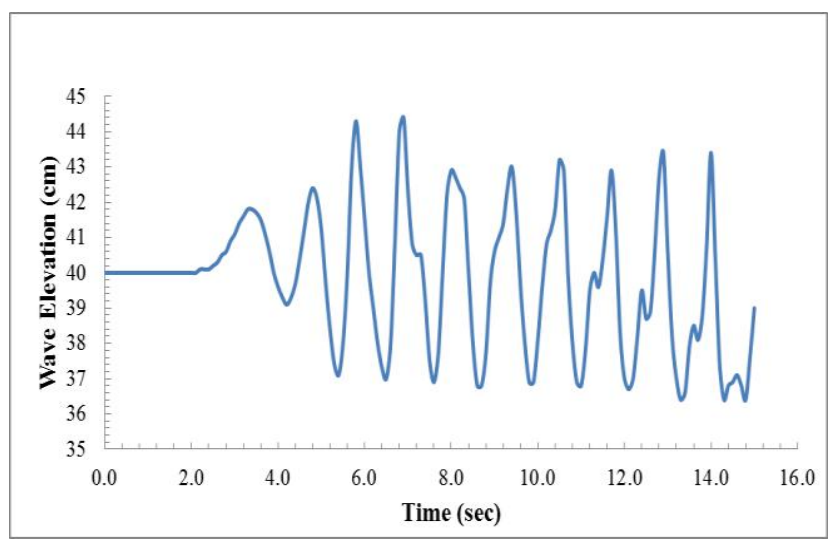

Fig. 6. Wave profiles using (Flow-3D) at wave period $(\mathrm{T})=1.2 \mathrm{sec}$ for perforated walls with square slots at behind model $(\mathrm{Ht})$.

Figure 7 shows a comparison of the efficiency of the suggested breakwaters' hydrodynamic output numerical results for various non - dimensional $(\mathrm{h} / \mathrm{L})$ at porosity $=50 \%$ and $\mathrm{B} / \mathrm{h}=1.0$. The figure showed that raising $\mathrm{h} / \mathrm{L}$ from 0.80 to 0.40 decreased $\mathrm{kt}$ for perforated walls with square slots, at $(\varepsilon)$ $=50$ percent and $\mathrm{B} / \mathrm{h}=1.0, \mathrm{~h} / \mathrm{L}$ rose from 0.11 to 0.33 . The transmission coefficients $(\mathrm{kt})$ for perforated walls with circular holes reduced from 0.65 to 0.30 for the same parameters, whereas $\mathrm{h} / \mathrm{L}$ increased from 0.11 to 0.33 . The reflection factor $(\mathrm{kr})$ rose as $\mathrm{h} / \mathrm{L}$ was reduced. For perforated walls with square holes, $(\mathrm{kr})$ rose from 0.30 to 0.40 as $\mathrm{h} / \mathrm{L}$ rose from 0.11 to 0.33 . For perforated walls with circular holes, $(\mathrm{kr})$ rose from 0.25 to $0.30 \mathrm{as} \mathrm{h} / \mathrm{L}$ rose from 0.11 to 0.33 .

The coefficient $(\mathrm{kd})$ for perforated walls with square openings increased from 0.70 to 0.88 , although it increased from 0.50 to 0.83 for perforated walls with circular openings. Based on the results, perforated walls with square openings outperform perforated walls with circular openings by $5 \%$ to $20 \%$. The empirical effects of the various hydrodynamic factors show that as the relative length $(\mathrm{h} / \mathrm{L})$ rises, the transmission factor $(\mathrm{kt})$ reduces, whilst the reflection and dissipation factors increase. 

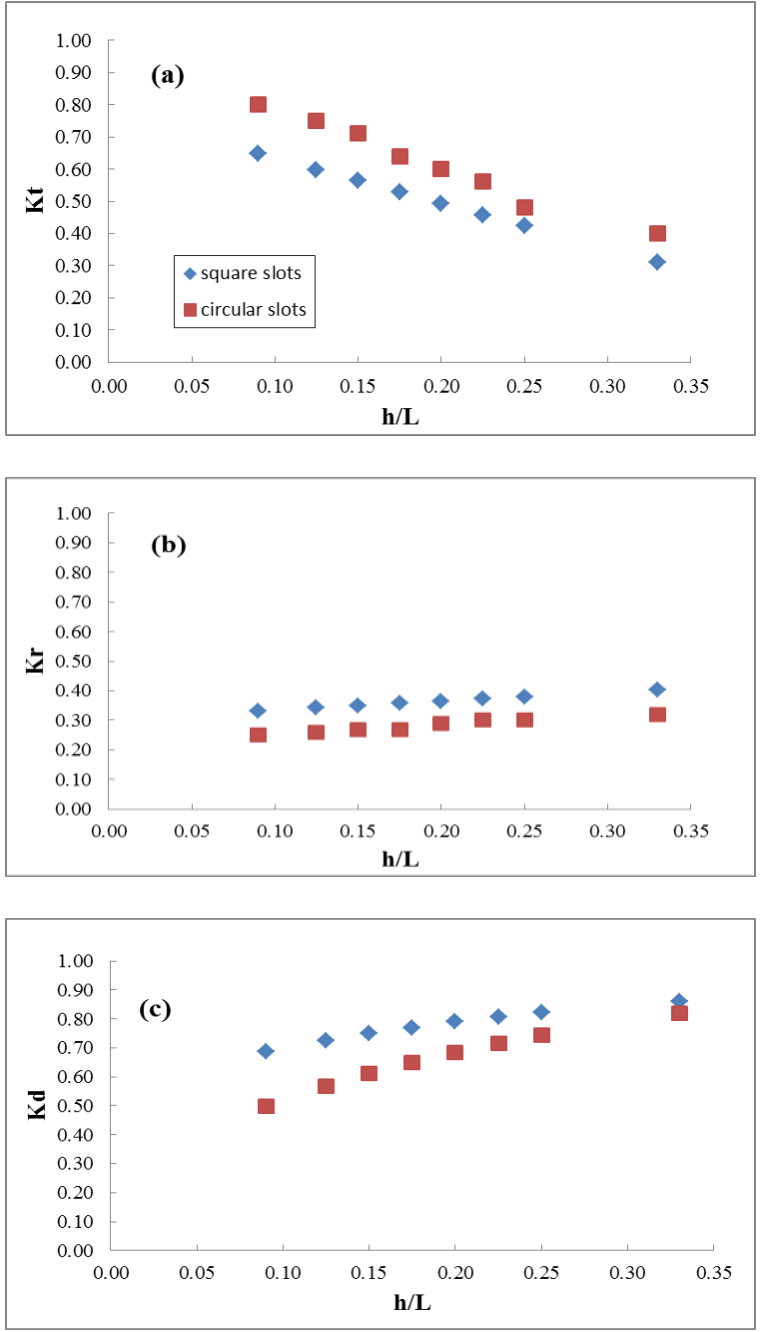

Fig. 7. Comparison between vertical walls with circular slots and vertical walls with square slots numerical results for $(\mathrm{h} / \mathrm{L})$ at $(\varepsilon)=50 \%$ and $\mathrm{B} / \mathrm{h}=1$ (a) $\mathrm{kt}$, (b) $\mathrm{kr}$ and (c)kd

Figure 8 illustrates how two vertical square holed walls compare to one wall in terms of performance. Single and double vertical perforated-wall transmitting, reflecting, and energy dissipation factors were studied as functions of $(\mathrm{h} / \mathrm{L})$, at $(\varepsilon)=50$ percent and $(\mathrm{B} / \mathrm{h}=1.0)$. The second breakwater has no noticeable influence on the reflection factor, but it does have a considerable influence on the transmission and energy dissipation factors, as expected. Because the second wall dissipates an additional fraction of the wave's energy, the transmission factor drops by up to $40 \%$ while the energy dissipation factor rises by up to $30 \%$.

Figure 9 compares the hydrodynamic efficiency of the current breakwater numerical model (square slots) to that of other related physical models studied by other authors, such as double rows of piles suspended horizontal c-shaped bars [8]. With increasing $\mathrm{h} / \mathrm{L}$, the transmission coefficient decreases, while the energy dissipation coefficient increases. The current breakwater (square slots) reduces the transmission coefficient by around $35 \%$ more than a previous equivalent physical model. The current breakwater computational model outperforms a related physical model [8] in terms of kt, kr, and kd values.
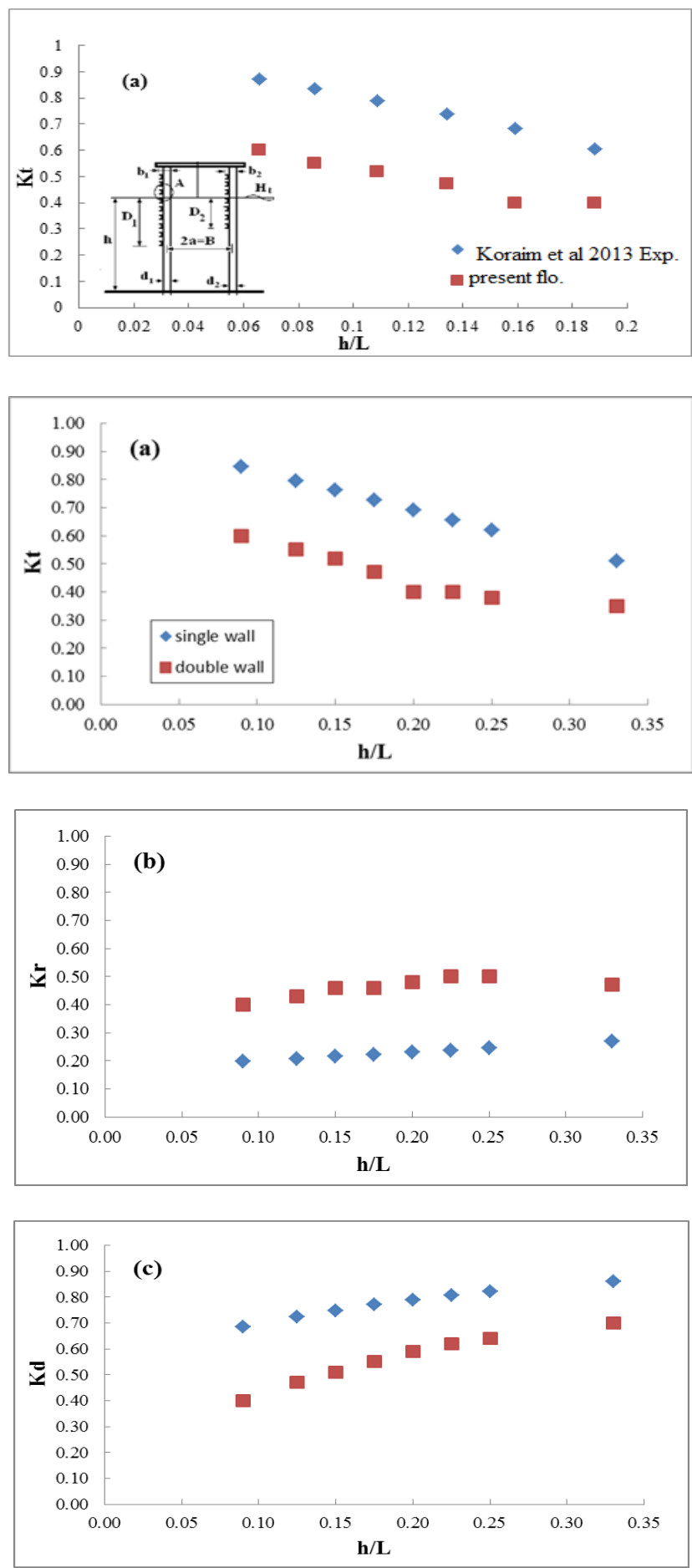

Fig. 8. kt, kr and kd for Comparison between single and double of perforated vertical walls with circular opening

At porosity $(\varepsilon)=0.25, \mathrm{~h} / \mathrm{L}$ rose from $(0.11)$ to $(0.33)$, and dimensionless wave forces $\mathrm{F} / \mathrm{Fo}$ rose from (0.2) to (1.08), as shown in figure 10. Nevertheless, the dimensionless wave forces $\mathrm{F} / \mathrm{Fo}$ increased from $(0.16)$ to $(0.75)$, at porosity $(\varepsilon)$ $=0.50$. The observed dimensionless wave forces $F / F o$, at porosity $(\varepsilon)=0.25$, was greater than at porosity $(\varepsilon)=0.50$ by 10 to $30 \%$. This happened in the permeable area at $\mathrm{B} / \mathrm{h}=1.0$ and $=50 \%$. As the relative length $(\mathrm{h} / \mathrm{L})$ rises, the horizontal wave force rises. 

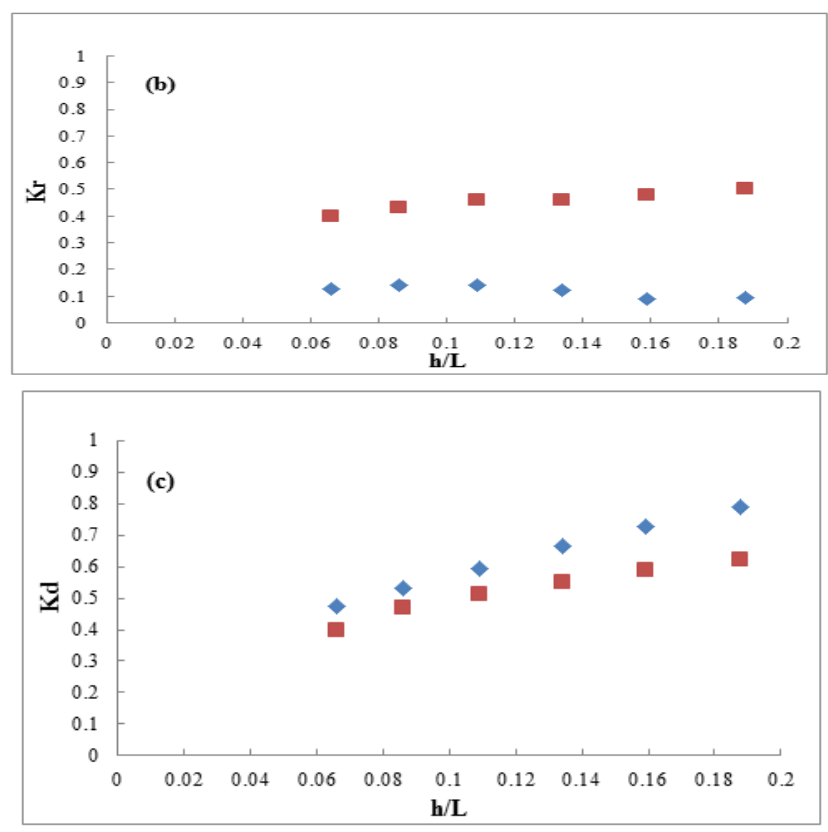

Fig. 9. Comparison (kt, $\mathrm{kr}$ and $\mathrm{kd}$ ) with (Koraim at al 2014) at $\mathrm{D} / \mathrm{h}=0.5$, $\mathrm{B} / \mathrm{h}=1, \varepsilon \mathrm{s}=0.5, \varepsilon \mathrm{p}=0.83$.

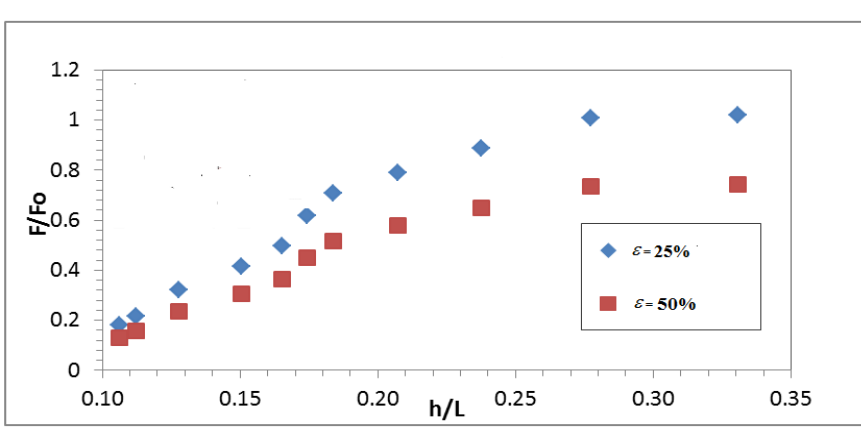

Fig. 10. Effect of horizontal wave force on a single wall with square slots at deferent porosity when $(\mathrm{f})=3$ and $(\mathrm{Cm})=0.0$.

Figure 11 shows the velocity distribution through slots in the following cases: quarter wave period, half wave period, and three quarters wave period. This was done to demonstrate how energy was lost. FLOW 3D's velocity vector and velocity field may be observed three times in figure 11 [12]. Higher velocities were found around the wave crests around the holes. Owing to the presence of the barrier, higher velocities are generated across the slots, causing the moving wave to contract.

In front of the breakwater, the velocity magnitude was exceedingly high, whereas behind it, it was incredibly low, as observed by the velocity vectors, a part of the wave energy was restricted, another part was transferred, and the remaining was dissipated as a vortex. Beyond a point proportional to the water level, the conveyed portion is redistributed along the complete depth. The barrier's immediate surroundings are considered by Flow 3D, while other regions are considered 2-dimensional flow.

The motion between the breakwaters was tumultuous, except the area near the holes, and the motion appeared to be vertical. The mean velocity field in the breakwater zone for $\mathrm{B} / \mathrm{h}=0.5$ at the vertical double perforated walls at $\mathrm{t}=10.25 \mathrm{~T}$, $t=10.50 \mathrm{~T}$, and $\mathrm{t}=10.75 \mathrm{~T}$ for the tenth wave cycle is shown in figure 11. Maximum velocities in the region of impermeable breakwaters were discovered to be $51.0 \mathrm{~cm} / \mathrm{s}$, as shown in figure 11. On the seaward side of the systems, where the predominant structure interaction occurs, intense vortices were discovered. The zone under the body of each barrier has a recirculating zone. For permeable breakwaters with a porosity $=0.50$, the first one is stronger and broader than the mean velocity zone. Under the same hydrodynamic conditions, this was found in the case of the impenetrable barrier. The recirculating zone was visible under the first barrier in this situation. The interaction of the water mass with the gaps on the body of the breakwaters was observed.
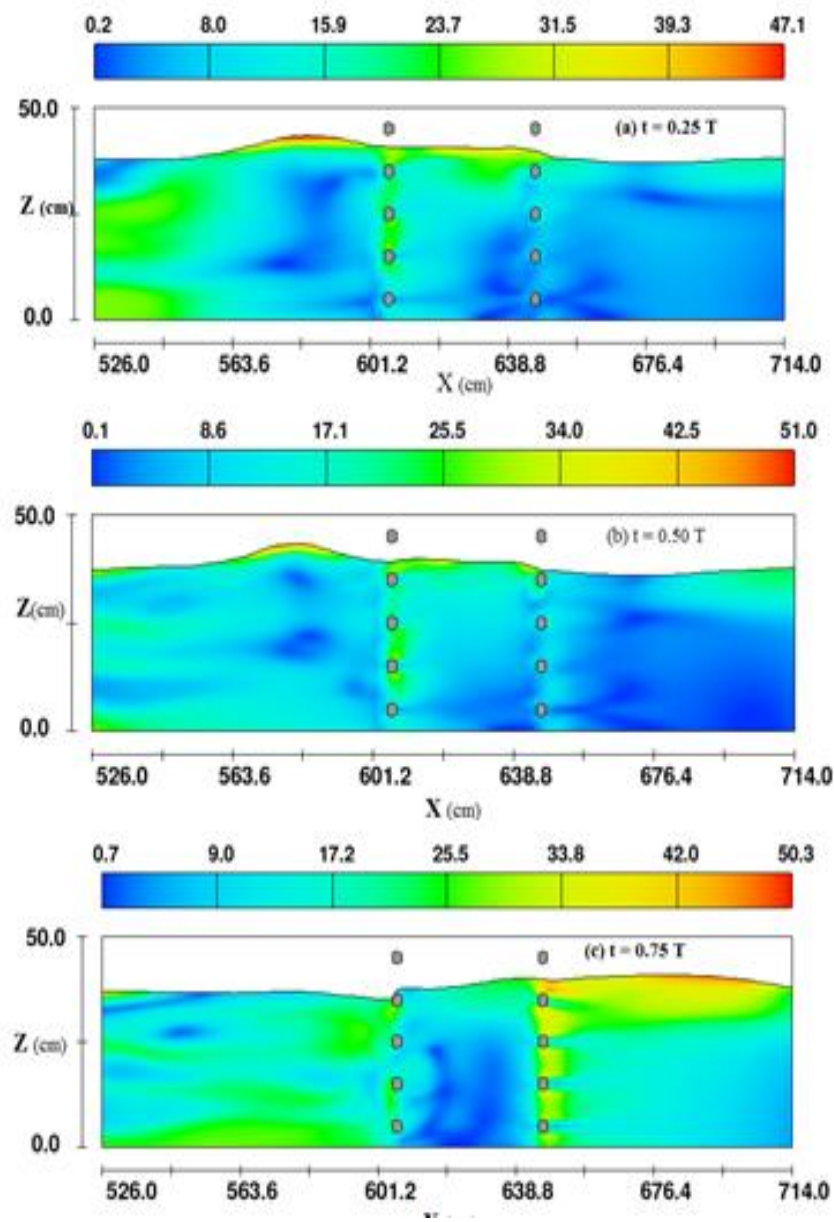

Fig. 11. Velocity distribution through slots at (a) quarter wave period, (b) half wave period and (c) three quarters wave period.

Also, figure 12 presents the vertical perforated wall in FLOW-3D. From the figure, it is obvious that FLOW-3D could compute the velocity that differs by changing the measurement location. In the same context, figure presents the distribution of $\mathrm{X}$-velocity at different probes for double vertical walls at $\mathrm{T}=1.20 \mathrm{sec}$ and $\mathrm{hi}=9 \mathrm{~cm}$. The velocity at the top was seen to be greater than the velocity at the bottom.

In figure 13 it is noted that the wave moves in a circular shape and the large circles are in the upper and then gradually lower down figure 14 the pressure distribution has two modes static or dynamic distribution. FLOW-3D could present both and could recognize their places of application. FLOW-3D could determine the force resulting from these pressures. 

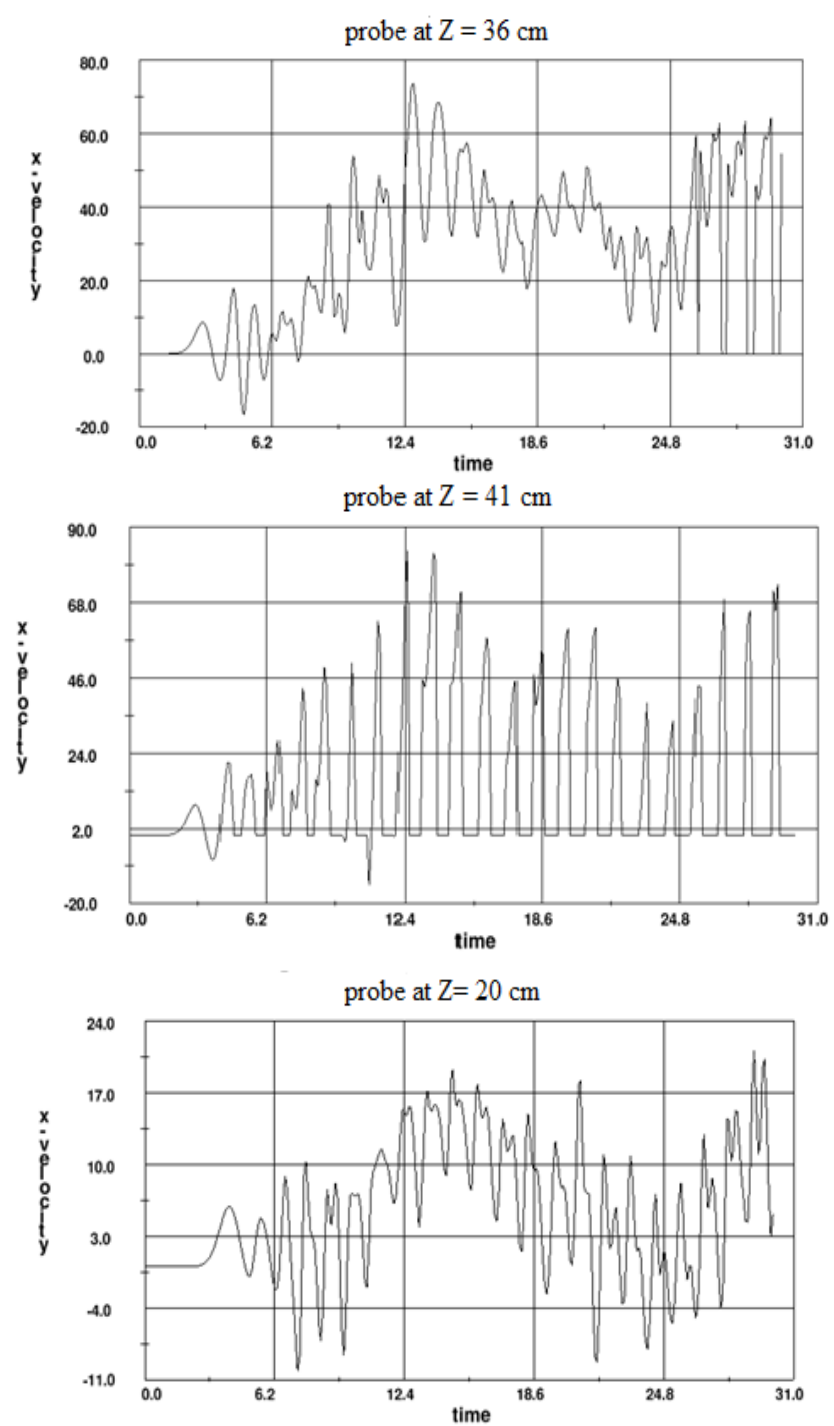

Fig. 12. Distribution of $X$-velocity at different probe for vertical perforated thin wall with circular slots at $\mathrm{T}=1.20 \mathrm{sec}$ and $\mathrm{hi}=9 \mathrm{~cm}$
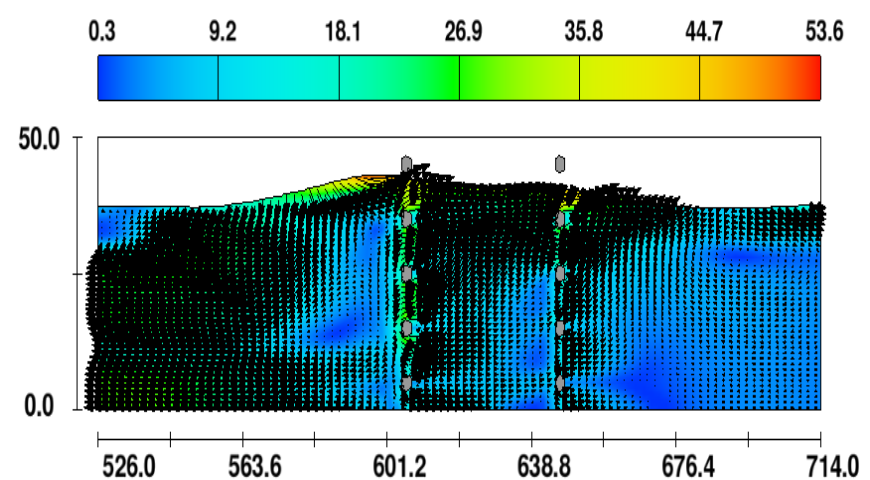

Fig. 13. Velocity vectors at front, between and behind barriers.

Figure 14 presents the static and dynamic pressure distributions. The figure indicated that the hydrostatic pressure increases as water depth increases and the hydrodynamic pressure increases as the energy losses coefficient increases. pressure contours

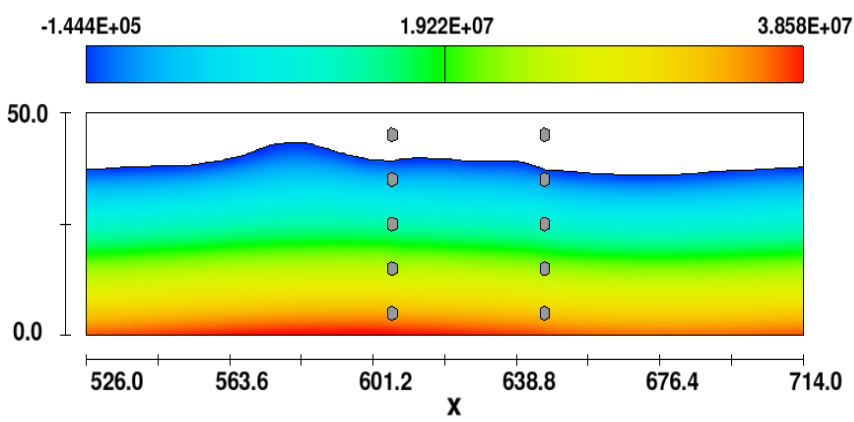

Fig. 14. Pressure field in the zone of vertical perforated wall (Porosity $=$ $0.50, \mathrm{~B} / \mathrm{h}=1.0$ and $\mathrm{Hi}=9 \mathrm{~cm}-\mathrm{T}=1.20 \mathrm{sec}$ )

\section{CONCLUSION\& RECOMMENDATIONS}

Based on the previous analysis of the obtained results, the conclusions which have been reached are as follow:

- The results and study revealed that Flow-3D has a strong capacity to describe the relationship of a wave with a linear wave with vertically perforated walls. It can also replicate the most important aspects of laboratory data and semi-analytical results. The numerical results produced by Flow $-3 \mathrm{D}$ are great.

- The transmission of waves is decreased by 5:20\% in square slots compared to circular slots.

- The use of a pair of circular slotted walls decreases wave transmission by up to $30 \%$ and increases wave energy dissipation by up to $40 \%$ as compared to a single wall.

- The horizontal wave force increases as the relative length $(\mathrm{h} / \mathrm{L})$ increases. At porosity $=0.25$, the relative wave forces $(\mathrm{F} / \mathrm{Fo})$ were 10 to $30 \%$ higher than at porosity $=0.50$.

- The wave moves in a circular shape and the large circles were in the upper and then gradually lower down.

- At the openings, the wave velocity was high, and the wave energy dissipation factor was also high; the higher the wave amplitude, the higher the wave energy dissipation factor.

\section{NOTATIONS}

In this paper, the following symbols were used:

- $\mathrm{Cm} \quad$ factor of mass applied;

- $\mathrm{g}=$ Gravitational acceleration;

- hi = height of the event wave;

- $\mathrm{hr}=$ height of mirrored waves;

- Ht = height of the wave that was transmitted;

- $\mathrm{Hr}=$ stands for the height of the reflected wave ;

- $\mathrm{Hi}=$ height of the incident wave;

- $\mathrm{h}=$ depth of the bath;

- $\mathrm{k} \quad=$ wave sum of the event;

- $\mathrm{kl} \quad$ = factor of energy dissipation;

- $\mathrm{kr} \quad$ = factor of reflection;

- $\mathrm{kt} \quad$ = factor of transmitting;

- $\mathrm{L}=$ length of wave;

- $\mathrm{T}=$ duration of the wave;

- $\mathrm{t}=$ time; 
- $\mathrm{x}, \mathrm{z}=$ axis in two dimensions;

- $\varepsilon=$ porosity of the first wall's bottom section;

- $\quad \phi p=$ possibility for overall flow velocity;

- $\phi 1=$ possibility for seaward velocity;

- $\phi 2=$ Between the two walls, there is a possibility for velocity.;

- $\phi 3=$ possibility for shoreward velocity and

- $\mathrm{F}^{*}=$ force of the waves.

\section{REFERENCES}

[1] Bahaa Elsharnouby and Mohamed, E. (2012). "Study of environment friendly porous suspended breakwater for the Egyptian Northwestern Coast" J. of Ocean Engineering, Vol. 48, 47-58.

[2] Huang Z. (2007) "Wave interaction with one or two rows of closely spaced rectangular cylinders" J. Ocean Eng Vol. 34,1584-1591.

[3] Huang, C. J.; Chang, H. H.; and Hwung, H. H., 2003. "Structural permeability effects on the interaction of a solitary wave and a submerged breakwater," Coastal Engineering. Vol. 49, pp. 1-24.

[4] Hsu, H-H. \& Wu, Y-C., 1999. "Numerical solution for the second-order wave interaction with porous structures." International Journal for Numerical Methods in Fluids, Vol. 29 Issue 3, pp. 265-288.

[5] Isaacson, M., Baldwim, J., Premasiro, S. and Yang, G., (1999) "Wave interaction with double slotted barriers.” J. Applied Ocean Research, Vol. 21, No. 2, pp. 81-91.

[6] Isaacson, M., Premasiro, S. and Yang, G. (1998) "Wave Interaction with Vertical Slotted Barrier" J. Waterway, Port, Coastal and Ocean Eng., ASCE, Vol. 124, No. 3.

[7] Ji, C.H. and Suh, K.D. (2010) "Wave interactions with multiple-row curtainwall-pile breakwaters" J.Coastal Engineering vol. 57 issue 5, p. $500-512$.
[8] Koraim, A. S., Iskander, M.M. and Elsayed, W. R. (2014) "Hydrodynamic performance of double rows of piles suspending horizontal c shaped bars" J. Coastal Engineering, Vol. 84, P. 81-96.

[9] Koraim, A. S., Iskander, M.M. and Elsayed, W. R. (2013) "Hydrodynamic performance of double rows of piles suspending horizontal c shaped bars" J. Coastal Engineering, Vol. 84, P. 81-96.

[10] Koraim, A. S. and Salem, T. N. (2012) "The hydrodynamic characteristics of a single suspended row of half pipes under regular waves" J. Ocean Engineering, Vol. 50, P. 1-9.

[11] Laju, K., Sundar, V. \& Sundaravadivelu, R., 2011. "Hydrodynamic characteristics of pile supported skirt breakwater models." Journal of Ocean Re, 33, 12-22.

[12] Lin, P.; and Karunarathna, .S.A., 2007. "Numerical study of solitary wave interaction with porous breakwaters," J. of waterway, port, coastal and ocean engineering. , pp. 352-363.

[13] Moh. Ibrahim (2017) "Linear Wave Interaction with Permeable Breakwaters" A Thesis Submitted for Partial Fulfillment of Doctor of Philosophy Degree in Civil Eng., al-Azhar University.

[14] Mansard, E .P. D. \& Funke, E. R., 1980. "The measurement of incident and reflected spectra using a least squares method." In Proc. 17th Coastal Eng. Conf., Sydney, Australia, pp 159-174.

[15] Nadji Chioukh et al (2017) "Reflection and Transmission of Regular Waves from/Through Single and Double Perforated Thin Walls" China Ocean Eng., 2017, Vol. 31, No. 4, P. 466-475.

[16] Rageh, O., Koraim, A. (2010b). "Hydraulic performance of vertical walls with horizontal slots used as breakwater". J.Coastal Engineering, Vol. 57, 745-746. 12.

[17] Suh KD, Jung HY and Pyun CK (2007) "Wave reflection and transmission by curtain wall-pile breakwaters using circular piles". J. Ocean Eng,Vol. 34(14-15), 2100-2106.

[18] Suh, K. D., Shin, S. \& Cox, D. T., 2006. "Hydrodynamic characteristics of Pile-Supported vertical wall breakwaters." J. of Waterways, Port, Coastal and Ocean Engineering, Vol.132, No.2, pp.83-96. 